\title{
Parasites as Bioindicator for Health Status and Environmental quality of Freshwater Fish species in Ekiti State, Nigeria
}

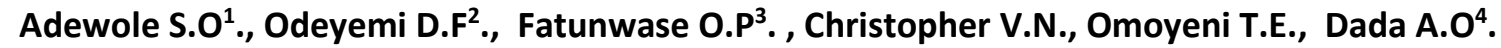
1, 3, 4 Department of Zoology and Environmental Biology, Faculty of Science, Ekiti State University, Ado Ekiti, Ekiti State

${ }^{2}$ Department of Science Laboratory Technology, Biotechnology option, Faculty of Science, Ekiti State University, Ado Ekiti, Ekiti State

profadewole@gmail.com

\begin{abstract}
The prevalence of parasites occurring on and in the internal organs of fish species was studied. Fish species (Oreochromis niloticus, Clarias gariepinus, Tilapia zilli) were randomly obtained from fishermen landing at the jetties of Ado, Ero, Ogbese, Ikun and Egbe dams, in Ekiti state. Samples were dissected; smears for the identification of ectoparasites were taken directly from the gills, operculum and skin. The parasites were excised, identified and counted. Nematode parasite with the total sum of 164(29.6\%) was the most abundant parasite occurring in all the dams. This was followed by Trichodina sp (Ciliophora) with total abundance value of $147(26.5 \%)$ in all the dams. Acanthocephalan, Gyrodactylus sp, Dactylogyrus sp, Diphyllobothrium latum and Clinostomum sp have abundance values of 26 (4.7\%), 27(4.9\%), 21(3.8\%), 146 $(26.4 \%)$ and $23(4.2 \%)$ respectively with Dactylogyrus sp (Monogenea) being least abundant, 21(3.8\%), in all the dams. The overall parasitic prevalence from the different dams showed that Ado dam had the highest parasitic infection with $27.3 \%$ which suggests that Ado dam has the lowest water quality. There is need for constant surveillance in rivers and reservoirs to detect early signs of parasitic infection. Viable preventive measures against fish parasitism in Nigerian freshwater bodies are highly recommended.
\end{abstract}

Keywords: Bioindicators, Dam, Fish, Parasites, Prevalence Freshwater,

\section{Introduction}

Parasites can be used as effective monitoring tools in environmental impact studies as they are able to accumulate certain pollutants at levels higher than those of their ambient environment [1]. Fish parasites serve as biological indicator to illustrate the ecology of their infected hosts. They have been connected to anthropogenic impact and environmental changes in freshwater habitat. Water pollution induces pathological changes in fish, thus fish species can be used as indicator of exposure to contaminants [2]. Fish is considered as one of the most significant indicators because they have long lifespan, which can be exploited in bio-accumulation studies. They occur at different trophic level in an aquatic food web (herbivores, omnivores, carnivores), they also occur ubiquitously, almost in all water, even polluted water. Fish can serve as definitive, intermediate or paratenic host in the life cycle of many species of metazoans, 
protozoans and crustacean parasites. Also, due to the fish species diversity, there is an increasing interest in using parasites as bioindicator of their fish host life conditions.

Environmental stressors such as wastewater or industrial pollutants can result in an increase in fish parasites due to a decrease in immunological defenses and a lesser resistance to infections. Water quality and season are the most important factors affecting the prevalence of parasites [3]. Pollutants might promote parasitism increasingly in aquatic animals; especially fish [4,5]. Metazoans, which are normally ectoparasites, are in constant contact with water, suggesting that poor water quality may adversely affect their diversity to a greater extent [6]

Parasites can be used to detect both heavy metals pollution and eutrophication in water [7]. Parasites are potential indicators of environmental quality due to the variety of ways in which they respond to anthropogenic pollution. They provide valuable information about the chemical state of their environment through their ability to concentrate environmental toxins within their tissues.

Conditions that predispose fish species to parasitic infections include reduced oxygen content of water, increase in organic matter in water, poor environmental condition. The effect of parasitic infection on fish species is influenced to a large extent by the type and number of parasite present.. The pathological conditions of parasites in fish includes anorexia (loss of appetite), resting at the bottom of water, changes in skin color, pale gills, increase in mucus production. Parasites of fishes include trematodes (flukes), cestodes (tapeworm), nematodes (roundworms), Acanthocephalan (thorny headed worms) and protozoans out of which trematodes and nematodes are the commonest. Knowledge of biology of parasite and its host, host-parasite relationship, and the environment can help to detect environmental change, particularly long living species (some digeneans, trematodes and cestodes life cycle stages), provide information on the seasonal migration of their host and migration habits of different age groups(feeding area/ spawning area). However, there can be a change in their abundance in the host of some of their life cycle stages which can be as a result of disappearance of their intermediate hosts, provoking disappearance of some parasite species under polluted conditions. The occurrence of heteroxenous parasites in an area affected by pollution can be related to the number of intermediate hosts at the studied sites [8].

Water quality and season are the most important factors affecting the prevalence and prevalence of parasites [3]. Pollutants might promote parasitism increasingly in aquatic animals; especially fish $[4,5]$. Certain parasites are able to accumulate heavy metals than their fish host's tissues or the environment. Due to this ability, they can be sensitive bio-indicator of environmental pollutants. Fish muscles and various mussel species are commonly used as bio-indicators. Studies have shown that there is specie-specific preference for metals in parasites' propensity to accumulate different pollutants, where certain parasite specie accumulates certain metals more intensively than other parasite species and viceversa.

Many indices are being used in aquatic environmental studies to determine the quality of water as well as fauna inhabiting the environment. Also, parasitic index in aquatic habitat can be linked with fish pathology components and other measures of fish health to assess the health status and environmental quality of fish. The use of fish parasites as bioindicators in aquatic environment has not been fully exploited like other indices hence the need for this study. 
Adewole S.O., Odeyemi D.F., Fatunwase O.P., Christopher V.N., Omoyeni T.E., Dada A.O.; Parasites as Bioindicator for Health Status and Environmental quality of Freshwater Fish species in Ekiti State, Nigeria. Journal of Biomedical Engineering and Medical Imaging, Volume 6, No 2, April (2019), pp 1-7

The objective of this study is to determine the prevalence of parasites found in different water bodies in Ekiti State and use the fish parasites metrics as a bio-indicator in determining the water quality.

\section{Materials and Method}

\subsection{The Study Area}

The study was carried out using fish samples collected from Ado Ekiti dam, Ero dam, Egbe dam, Ogbese River, Ikun-Ekiti dam. Ado-Ekiti dam was constructed on Ureje river in Ado Ekiti. It is located on latitude $7^{\circ} 37^{i}$ North and Longitude $5^{\circ} 36^{i}$ East of the equator. Ero dam is an earth filled embankment with a length of $662 \mathrm{~m}$ and an impoundment area of $45 \mathrm{~km}$, located in Ikun Ekiti between Latitude $7^{\circ} 15^{i}-8^{\circ} 5^{i}$ and Longitude $4^{\circ} 45^{i}-5^{\circ} 45^{i}$. Egbe dam which originated from Kwara State and flows north to south through Ode-Ekiti to Egbe- Ekiti, located at $7^{\circ} 36^{i}$ North and Longitude $5^{\circ} 36^{i}$ east of the equator.

\subsection{Sample Collection:}

The fish species collected and identified according to Idodo- Umeh (2003). The fish species were identified as Clarias gariepinus, Tilapia zilli, and Oreochromis niloticus. They were bought for 3 months from local fishermen at the water sites as soon as they landed and transported to the laboratory using big plastic container, making sure the samples were still alive. The smears for the identification of ectoparasites were taken directly from the gills, operculum and skin while dissections were done to observe the intestine for possible detection of endoparasites.

\subsection{Experimental procedures}

External surface of the fish was examined using a hand lens for ectoparasites species. The smears from the gill surface and operculum were stained using silver nitrate impregnation. They were rinsed and covered with $5 \%$ silver nitrate $\left(\mathrm{AgNo}_{3}\right)$ solution and impregnated for 30 minutes in the dark. The silver nitrate was removed and the slides were covered with distilled water, exposed to light for 40-50 min and dried after exposure.

For identification purposes, Nematoda was dehydrated in a graded ethanol series and transferred to $100 \%$ glycerine (Riemann, 1988). Digenea, Monogenea and Cestoda were stained with acetic carmine, dehydrated, cleared with eugenol and mounted in Canada balsam (Palm, 2004). The identification of the parasites species on the slides were done or carried out under light based on the shape and size of the sclerotized part when they are mounted using Canada balsam and stained with Acetic carmine for monogeneans and cestodes.

For Endoparasites, the fish samples were laid on a dissecting board, the mouth, fins and dorsal cavity well clamped down with entomological pins. The dorsl side was symmetrically opened with the aid of surgical blades to show the alimentary canal. The intestine, stomach, liver, heart, gall bladder were carefully excised for parasites examination. Gonads were excised carefully using forceps into the petridish filled with $10 \%$ normal saline for 20 minutes. Parasites that appear on the surface of the normal saline in the petri-dish were extracted using a dropper and was placed on a microscope slide which was viewed under a compound microscope with magnification (x40). The following parasites were identified: Nematodes, Cestodes, Trematodes, Acanthocephalan. 


\subsection{Statistical Analysis}

Analysis of variance was used to determine the significance of each parasite in each dam. Relative abundance was calculated as: species of a parasites / Total specimen $\times 100$. Both descriptive and inferential statistics were employed to analyze results.

\section{Results}

\subsection{Parasite abundance}

Nematode parasite with the total sum of $164(29.6 \%)$ was the most abundant parasite occurring in all the dams. This was followed by Trichodina sp (Ciliophora) with total abundance value of $147(26.5 \%)$ in all the dams. Acanthocephalan, Gyrodactylus sp, Dactylogyrus sp, Diphyllobothrium latum and Clinostomum sp have abundance values of 26 (4.7\%), 27(4.9\%), 21(3.8\%), 146 (26.4\%) and 23(4.2\%) respectively with Dactylogyrus sp (Monogenea) being least abundant, 21(3.8\%), in all the dams as shown in Table 1.

Table 1: Represents the percentage abundance of each parasite in the study areas.

\begin{tabular}{|l|l|l|l|l|l|l|}
\hline Parasite/Study Area & Ikun Dam & Ado Dam & Ero Dam & Egbe Dam & Ogbese dam & Total \\
\hline $\begin{array}{l}\text { Trichodina sp } \\
\text { (Ciliophora) }\end{array}$ & - & $\begin{array}{l}17.00 \\
11.2 \%\end{array}$ & $\begin{array}{l}49.00 \\
53.8 \%\end{array}$ & $\begin{array}{l}81.00 \\
64.3 \%\end{array}$ & - & $\begin{array}{l}147 \\
26.5 \%\end{array}$ \\
\hline Acanthocephalan & - & 26 & - & - & - & 26 \\
& & $17.2 \%$ & & & $4.7 \%$ \\
\hline $\begin{array}{l}\text { Gyrodactylus sp } \\
\text { (Monogenea) }\end{array}$ & - & 3.00 & 9.00 & 15.00 & - & 27 \\
\hline $\begin{array}{l}\text { Dactylogyrus sp } \\
\text { (Monogenea) }\end{array}$ & - & 5.00 & $8.9 \%$ & $11.9 \%$ & & $4.9 \%$ \\
\hline $\begin{array}{l}\text { Clinostomum sp } \\
\text { (Trematoda) }\end{array}$ & - & $3.3 \%$ & 8.00 & 8.00 & - & 21 \\
\hline $\begin{array}{l}\text { Diphylobotrium } \\
\text { latum } \\
\text { (cestoda) }\end{array}$ & 28 & $2.6 \%$ & 9.00 & 10.00 & - & $3.8 \%$ \\
\hline $\begin{array}{l}\text { Camallanus sp } \\
\text { (Nematoda) }\end{array}$ & $40 \%$ & $14.6 \%$ & $6.9 \%$ & $7.9 \%$ & & 23 \\
& $60 \%$ & 74.00 & 3.00 & 87 & 146 \\
\hline Total & $49 \%$ & 10.00 & $9.4 \%$ & $75 \%$ & $26.4 \%$ \\
& 70 & $11.0 \%$ & $7.1 \%$ & $25 \%$ & 164 \\
\hline
\end{tabular}

The overall parasitic prevalence from the different dams showed that Ikun dam has the least parasitic infection with $12.6 \%$ of the total and Ado dam had the highest parasitic infection with $27.3 \%$ as shown in Table 2.

Table 2: Percentage prevalence of parasites in the study areas.

\begin{tabular}{|l|l|l|l|l|l|l|}
\hline Parasite/Study Area & Ikun Dam & Ado Dam & Ero Dam & Egbe Dam & Ogbese dam & Total \\
\hline $\begin{array}{l}\text { Trichodina sp } \\
\text { (Ciliophora) }\end{array}$ & - & 17.00 & 49.00 & 81.00 & 147 \\
\hline Acanthocephalan & - & 26 & - & - & - & 26 \\
\hline $\begin{array}{l}\text { Gyrodactylus sp } \\
\text { (Monogenea) }\end{array}$ & - & 3.00 & 9.00 & 15.00 & - & 27 \\
\hline Dactylogyrus sp & - & 5.00 & 8.00 & 8.00 & - & 21 \\
\hline
\end{tabular}


Adewole S.O., Odeyemi D.F., Fatunwase O.P., Christopher V.N., Omoyeni T.E., Dada A.O.; Parasites as Bioindicator for Health Status and Environmental quality of Freshwater Fish species in Ekiti State, Nigeria. Journal of Biomedical Engineering and Medical Imaging, Volume 6, No 2, April (2019), pp 1-7

\begin{tabular}{|l|l|l|l|l|l|l|}
\hline \hline $\begin{array}{l}\text { (Monogenea) } \\
\begin{array}{l}\text { Clinostomum sp } \\
\text { (Trematoda) }\end{array}\end{array}$ & - & 4.00 & 9.00 & 10.00 & - & 23 \\
\hline $\begin{array}{l}\text { Diphylobotrium } \\
\text { latum } \\
\text { (cestoda) }\end{array}$ & 28 & 22 & 6.00 & 3.00 & 87 & 146 \\
\hline $\begin{array}{l}\text { Camallanus sp } \\
\text { (Nematoda) }\end{array}$ & 42 & 74 & 10.00 & 9.00 & 29 & 164 \\
\hline $\begin{array}{l}\text { Total } \\
\text { parasites/percentage }\end{array}$ & \begin{tabular}{l}
$70.6 \%$ \\
\hline
\end{tabular} & $\begin{array}{l}151 \\
27.3 \%\end{array}$ & $\begin{array}{l}91.00 \\
16.42 \%\end{array}$ & $\begin{array}{l}126.00 \\
22.7 \%\end{array}$ & $\begin{array}{l}116 \\
20.9 \%\end{array}$ & $\begin{array}{l}554 \\
100 \%\end{array}$ \\
\hline
\end{tabular}

\section{Discussion}

The result showed nematode (Camallanus $\mathrm{sp}$ ) to be the most prevalent parasite with abundance value of $164(29.6 \%)$ at all locations throughout the study period. The high rate of fish susceptibility to Camallanus sp. observed in this research is in agreement with the findings of [9]. [10] observed that intestinal parasites appears to be more sensitive bio-accumulators of heavy metals than their fish hosts, and may serve as excellent indicators of heavy metal pollution in relation to water quality. Thus, the presence of particular parasites in a host may tell us something about the stability of the ecosystem. The high rate of Gyrodactylus sp susceptibility reported in study was as a result of the compromised dermal tissue that the fish samples present. This follows [11] report on excessive mucus secretion, epithelial proliferation and dermal erosion of fin fish. It could be as a result of their high population density or environmental degradation of their habitat. [12] reported that in high population density along the coasts and significant anthropogenic stress in terms of population and environmental degradation, fish can describe the environmental condition of their habitat. According to[9] the cichlids harbor majority of infection which include adult digenea infecting different tissues; trematodes metacercariae of the family clinostomatidae encysting in the tissue and adult monogenea of the families Dactylogyridae and Gynodactylidae infecting the gills and the skin of tilapia species. This shows that it could be easy to identify fish samples with compromised dermal tissues that may bear Gyrodactylus sp and avoid them during market purchase in order to prevent human transmission of possible infection. This research findings show the presence of Clinostomum sp. and Diphylobotriumlatum in significant quantity. This is in agreement with [13] and [9].

Nematode parasite (Camallanus sp) was found in large quantity 164 (29.6\%) in the fish host across all the study areas, as earlier observed by[14] who reported nematodes as the most common parasites infecting $18.6 \%$ of fish population. Ado Dam has the highest population of parasites with percentage abundance value of $27.3 \%$ compared to the other dams, this can further show the level of environmental quality of water in the dam [7]. It was also observed in this study that adult fishes are more susceptible to parasitic infections than juveniles. This corroborates the findings that the longer and bigger the fish, the greater the susceptibility to parasitic infection.

\section{Conclusion and Recommendation}

It is recommended that there should be further studies of wider scope on other fish species found in many Nigerian diets. Also in order to control parasites in fish culture system, it is recommended that lining of the ponds should be done before stocking. There should be constant surveillance and observation of fish behavior in rivers and reservoirs to detect early signs of parasitic infection. Also, weeds and various types 
of vegetation should be removed to ensure digenean flukes intermediate hosts'control. Fish density control is recommended as well as selective cropping and prompt removal of infected fish to avoid rapid spread of infection.

This research showed that Ado dam has the lowest water quality as compared to the other dams. The economic impact of these parasites on fish as an article of trade would lead to better policy decision on how to protect Nigeria`s aquatic resources. A comprehensive knowledge of the biology of host parasite relationship is therefore, imperative.

\section{REFERENCES}

[1] Milen Nachev and Bernd Sures Environmental parasitology: parasites as accumulation bioindicators in the marine environment. Journal of Sea Research 2016. 113: 45-50.

[2] Bernet, D.H. Schmidt, W. Meier, P. Burkhardt-Holm and T. Wahl. Histopathology in fish proposal for a protocol to assess aquatic pollution. Journal of Fish diseases 1999. 22: 25-34

[3] Authman, M.M.N., E.M. Bayoumy and A.M. Kenawy. Heavy metal concentrations and liver histopathology of Oreochromis niloticus in relation to aquatic pollution. Global Veterinaria, 2008 2: 110-116.

[4] Khan, R.A. and S.M. Billiard,.Parasites of winter flounder (Pleuronectes americanus) as an additional bioindicator of stress-related exposure to untreated pulp and paper mill effluent: A 5-year field study. Archives of Environmental Contamination Toxicology 2007 52: 243-25

[5] Oros, M. and V. Hanzelova,. Re-establishment of the fish parasite fauna in the Tisa River system (Slovakia) after a catastrophic pollution event. Parasitology Research., 2009 104: 1497-1506

[6] Pietrock, M., T. Meinelt and D.J. Marcogliese,. Effects of cadmium exposure on embryogenesis of Stagnicola elodes (Mollusca, Gastropoda): Potential consequences for parasite transmission. Archives of Environmental Contamination Toxicology 2008 55: 43-48.

[7] Lafferty, K. D; Ecosystem Consequences of Fish Parasites, Journal of Fish biology, 2008 73, 2083-2093.

[8] Overstreet, R.M. Parasitological Data as Monitors of Environmental Health. Parasitologia, 1997. 39;169175

[9] Paperna, I. Parasites, Infections and Diseases of Fishes in Africa. FAO, Rome, Italy, 1980: 216

[10] Sures, B. The Use of Fish Parasites as Bioindicator of Heavy Metals in Aquatic Ecosystems: A review. Aquatic. Ecology. 2001 35:245-255

[11] Paperna, I. Parasites, Infections and Diseases of Fishes in Africa, an update. CIFA Tech paper, 1996. 31; 1200 
Adewole S.O., Odeyemi D.F., Fatunwase O.P., Christopher V.N., Omoyeni T.E., Dada A.O.; Parasites as Bioindicator for Health Status and Environmental quality of Freshwater Fish species in Ekiti State, Nigeria. Journal of Biomedical Engineering and Medical Imaging, Volume 6, No 2, April (2019), pp 1-7

[12] Ruckert, S. Hagen, W. Yunair, A.T. and Palm, H.W,: Metazoan Parasites of Fishes and their potential use as a Bioindicator in the SegaraAnakan. Lagoon, Indonesia. Regional Environmental change 2009. 9;315328

[13] Ashade, O.O., Shineye, O.M, and Kunoye, E.A.; Isolation, Identification and Prevalence of Oreochromis niloticus in three selected river sytems. Journal of Fisheries and Aquatic science. 2013. 8(1):115-121, 2013 Academic Journal Inc. 2013.

[14] Okaka, C.E. and Omoigberale, O.M.; Parasites of Fishes of Okhuaohe River, Edo State. African Health.Sciences 2002 3;1-2 